\title{
História da eletrificação no estado de São Paulo: um vocabulário controlado para a representação e recuperação da informação
}

DOSSIER ELETROMEMÓRIA: PAISAGEM E HisTóRIA

\section{Vânia Mara Alves Lima}

Bibliotecária [USP] e Dr. Sc. em Ciências da Comunicação [USP]. Professora Doutora em Ciência da Informação, Departamento de Biblioteconomia e Documentação, ECA/USP. São Paulo [SP] Brasil. <vamal@usp.br>.

\section{Cristina Hilsdorf Barbanti}

Historiadora [USP], Mestranda em Informação e Cultura no Programa de Pós Graduação em Ciência da Informação, ECA/USP. São Paulo [SP] Brasil. <crishb@usp.br>.

\section{Resumo}

As propostas teórico-metodológicas utilizadas para a construção de um vocabulário controlado da História da Energia Elétrica no Brasil, pela equipe de Ciência da Informação do projeto Eletromemória, são aqui apresentadas. 0 artigo aproxima os conceitos da Documentação, da Terminologia e também da Lógica e da Linguística, para organização e representação da informação coletada na pesquisa.

\section{Palavras-chave}

História da Energia Elétrica, documentação, vocabulário controlado, terminologia.

\section{History of Electrification in the state of São Paulo: a controlled vocabulary for the representation and retrieval of information}

\begin{abstract}
It is presented here the propose methodological theory used by the Information Science team of the Eletromemória Project to the construction of a controlled vocabulary of Electricity History. The article approaches the concepts of Documentation, Terminology, Logic and Linguistics, for organization and representation of the information collected in the survey.
\end{abstract}

\section{Keywords}

Electricity History, documentation, controlled vocabulary, terminology. 


\section{Introdução}

O Projeto Eletromemória teve início em 2007 com o objetivo de mapear os acervos bibliográficos, arquivísticos e museológicos que estão relacionados à implantação e ao desenvolvimento da geração, transmissão e distribuição da energia elétrica no Estado de São Paulo. Subsidiado pela Fundação de Amparo à Pesquisa do Estado de São Paulo, em sua primeira fase, sob o título História da Energia Elétrica no Estado de São Paulo Acervos Documentais (1890/2005), contou com o apoio da Fundação Patrimônio Histórico da Energia e Saneamento (FPHES) e, desde o início, suas atividades têm sido planejadas e implementadas por pesquisadores das principais universidades de São Paulo, a USP, a UNESP e a Unicamp.

Denominado Eletromemória I, de 2007 a 2009, o projeto buscou mapear o acervo histórico do setor elétrico paulista sob a guarda da FPHES, bem como o patrimônio histórico das seguintes empresas elétricas: AES Eletropaulo, AES Tietê, Cesp, CTEEP, Duke Energy.

0 tratamento documental diferenciado, não só nas diversas instituições, mas também dentro de uma única instituição, de livros, fotografias, peças de museu, relatórios técnicos, mapas, desenhos de arquitetura, entre outros, dificultava a recuperação da informação ali registrada e, a consequente produção historiográfica sobre o assunto. Portanto, era necessário estruturar a criação de um banco de dados de referência dos documentos existentes nas empresas, para posteriormente, disponibilizálo na web. Para poder tornar público os conteúdos informacionais, referente à energia elétrica, nos acervos mapeados, o grupo de documentação do Eletromemória I deveria construir um instrumento que permitisse representar e recuperar a informação ali existente de maneira abrangente, precisa e uniforme. Assim, em 2008 iniciou-se a construção de um vocabulário controlado em energia elétrica, que teve sua primeira versão incluída na base de dados Enerweb, a qual reúne os registros dos acervos arquivístico, bibliográfico e museológico da FPHES.

Em 2012 foi submetido à Fapesp o projeto História da Energia Elétrica no Estado de São Paulo (1890-1960): Patrimônio Industrial, Paisagem e Meio-Ambiente, o qual pela conexão com o anterior será aqui referido como Eletromemória II. Neste projeto, pretende-se completar e ampliar o mapeamento e o escopo do acervo documental relacionado à implantação do setor de energia elétrica no estado de São Paulo, a ser estruturado em banco de dados disponibilizado para consulta pública, dando continuidade ao Projeto Eletromemória I.

O Eletromemória II amplia o mapeamento dos acervos documentais, incluindo os de outras empresas elétricas, tais como CPFL, EMAE e uma série de pequenas concessionárias, cujas unidades geradoras foram implantadas de 1890 a 1960 e que tiveram o papel fundamental de alimentar e acelerar a industrialização do estado paulista. Esse mapeamento está sendo feito através da realização de pesquisas de campo nas unidades geradoras de eletricidade e em acervos públicos e privados para diagnosticar os patrimônios arquivístico, industrial, de cultura material e de potencial museológico, indicando seu estado de organização e conservação, além de pensar sua relação geograficamente com o entorno e sua transformação no tempo. A estruturação das pesquisas de campo terá por base o vocabulário controlado elaborado para o Projeto Eletromemória I, complementado por novos termos advindos dos campos de Patrimônio Industrial/Museologia e Paisagem/Meio Ambiente.

A seguir descrevemos o quadro referencial teórico e metodológico que nortearam a elaboração deste vocabulário controlado e os procedimentos metodológicos realizados até o presente momento.

\section{Quadro referencial teórico}

O conceito de vocabulário controlado aqui utilizado remete ao de tesauro documentário, instrumento em que os termos de um domínio se relacionam a partir de relações hierárquicas, associativas e de equivalência sinonímica ou quase-sinonímica. Essas relações só podem ser estabelecidas a partir das definições de cada um dos termos, ou seja, da especificação do significado daquele termo em relação aos demais no interior do domínio. Por isso o processo de construção de um vocabulário controlado pela Documentação, não é possível sem um diálogo com a Terminologia campo de estudos que se 
preocupa com a organização de sistemas de conceitos, pois como bem coloca Barité Roqueta (2001) não se concebe o surgimento e o desenvolvimento de nenhuma ciência ou disciplina que não esteja sobre uma plataforma de conceitos organizados em um sistema, pois os conceitos existem desde que o homem teve a capacidade de tomar da realidade elementos significativos e intrínsecos de cada objeto ou fenômeno, e de associar ou dissociar esses elementos em função de semelhanças ou diferenças. Portanto, sem a compreensão do significado de cada conceito e sua relação com os demais conceitos que constituem uma ciência, não há produção de novos conhecimentos.

No caso da Energia Elétrica também existe um conjunto de conceitos que têm significados particulares, se analisados comparativamente a outras áreas. Por esse motivo, não basta listar alfabeticamente os termos utilizados pelas instituições para representar o conteúdo informacional de seus acervos, foi necessário articular as propostas da Documentação, da Terminologia e também da Lógica e da Linguística, para usar a noção de relação como meio de, simultaneamente, conferir uma estrutura ao conjunto de termos e dar-lhes um significado razoavelmente preciso e compartilhado dentro do domínio proposto (LIMA, 2009).

Da Lógica utilizam-se as noções conjunção e disjunção, o que auxilia a determinar em que categoria se deve incluir determinado termo, a partir dos enunciados que podemos estabelecer sobre ele. Da Linguística, em particular da semântica estrutural, discute-se abstratamente as questões das relações entre expressões na língua geral. A Terminologia fornece princípios metodológicos para delimitar áreas de atividade e domínios do saber a partir da definição dos termos (BARROS, 2004). A Documentação, por fim, operacionaliza os conhecimentos acima para produzir instrumentos que permitam representar e recuperar documentos.

Assim, parte-se do princípio de que são as relações lógico-semânticas que garantem uma organização conceitual dos termos de um vocabulário controlado e que essas relações são inferidas a partir das definições dos termos que constituem a linguagem de especialidade de determinado domínio, isto é, da sua terminologia. Para garantir o acesso à informação representada por um vocabulário controlado é preciso também levar em conta as variações linguísticas, isto é, diferentes unidades linguísticas com o mesmo significado, os sinônimos e diferentes unidades linguísticas com significados próximos, os quase-sinônimos. Aqui impõem-se a necessidade do estabelecimento de relações de equivalência entre essas unidades linguísticas, garantido tanto diferentes pontes de acesso para a mesma informação quanto a economia do sistema.

\section{Procedimentos metodológicos}

No Eletromemória I foi realizado um levantamento dos descritores utilizados pelas bibliotecas, museus e arquivos da Fundação Patrimônio Histórico Energia e Saneamento para representar os conteúdos dos seus documentos. Neste levantamento foram obtidos 7458 termos que representavam 65 diferentes áreas do conhecimento dentre os quais foram selecionados os domínios Energia e Energia elétrica, com respectivamente 266 e 1110 termos associados ao foco temático do projeto. Foram então estabelecidas relações hierárquicas, associativas e de equivalência entre os descritores selecionados com base nas terminologias e nas obras lexicográficas do campo da Energia elétrica utilizando o software THEW32.

O software TheW32 foi selecionado para a estruturação e relacionamento dos termos por se tratar de software didático e gratuito. Ele é um programa em 32 bits para Windows desenvolvido por Timothy Craven, professor da "The University of Western Ontário" para desenvolvimento e manutenção de tesauros, disponível para acesso em <http://publish.uwo.ca/ craven/thew32/ thew32.htm>. Com o TheW32 era possível consultar os termos e seus relacionamentos e visualizar todo o vocabulário controlado, tanto em ordem hierárquica e quanto em ordem alfabética.

A base de dados da FPHES foi elaborada por empresa contratada pela instituição para realizar seu gerenciamento e manutenção, assim, o trabalho realizado pelo Eletromemória I foi transferido à empresa que procedeu a sua inserção na base. Infelizmente, não é possível aferir o uso desse 
instrumento pelos acervos da FPHES, pois o vocabulário não foi disponibilizado na web para o público em geral, permanecendo apenas em sua intranet.

Devido à ampliação do escopo temático no Eletromemória II, onde os processos históricos envolvendo a eletrificação no Brasil devem ser aflorados e representados pelos termos coletados ao longo das pesquisas, foi necessário proceder a um recorte mais específico nos termos levantados e hierarquizados no Eletromemória I, que se referiam majoritariamente as relações semânticas e conceituais dos processos técnicos concernentes à geração, transmissão e distribuição de energia elétrica.

Para tal, foram selecionados apenas os descritores específicos referentes à História da Energia Elétrica, os quais devem ser categorizados e relacionados aos termos específicos dos novos eixos que integram o projeto, a Paisagem e Ambiente e o Patrimônio Industrial em seus aspectos históricos e museológicos e que vem sendo obtidos a partir da pesquisa de campo para coleta de dados com relação aos processos de eletrificação no estado de São Paulo.

Para proceder a essa inclusão de novos termos relacionados à Paisagem/Ambiente e ao Patrimônio Industrial/Museologia observou-se a necessidade da redefinição do escopo do vocabulário controlado no âmbito do Eletromemória II. Uma série de medidas foi tomada para melhor definir o núcleo semântico, as categorias, de cada um dos novos eixos, e as relações existentes entre os seus termos. Realizou-se um encontro entre os pesquisadores do projeto para que fosse elaborado um mapa conceitual do Eletromemória.

Mapa conceitual pode ser entendido como um grupo ordenado de proposições sobre um determinando assunto que, visualizado em forma de árvore permite o entendimento das relações entre os conceitos conectados estimulando a solução de problemas e possibilitando a percepção de diferentes caminhos dentro de um mesmo conjunto. (FENDRICH; PEREIRA, 2006; ROVIRA, 2005). Dessa maneira foi possível identificar as categorias principais do vocabulário e algumas subcategorias, sob o ponto de vista da interdisciplinaridade de seus eixos. Assim, o chamado Top Term, ou termo que identifica o domínio, isto é, seu signo fundamental é "História da Energia Elétrica" a partir do qual organizam-se as principais categorias, a saber, "Patrimônio Industrial", "Paisagem e Ambiente", "Processos de Eletrificação" e "Documentação". No exemplo, a categoria Processos de Eletrificação, subdivide-se nas subcategorias: "Geração", "Distribuição e Transmissão", "Consumo"; "Cultura da Eletrificação" e "Instituições". Pode-se visualizar essa primeira hierarquia a seguir:

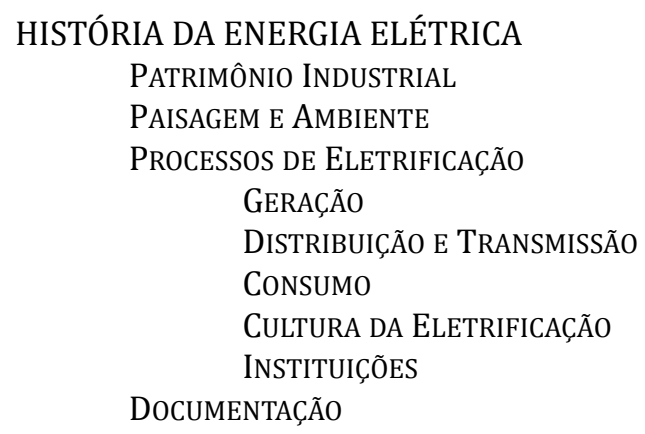

A próxima etapa será reorganizar sob essas categorias e subcategorias os termos já coletados e realizar a coleta dos termos nos relatórios e materiais fotográficos produzidos durante a pesquisa de campo na fase atual do projeto. Esses termos serão inseridos na estrutura hierárquica a partir das suas definições, ou seja, a partir da definição do termo, infere-se a sua posição na hierarquia devido as características comuns, que permitem a conjunção com outros termos da mesma categoria, ao mesmo tempo que as características disjuntivas entre eles estabelecem os limites da categoria.

A organização estrutural dos termos ancorados em relações lógico-semânticas, definidas a partir das terminologias dos domínios que compõem o vocabulário é uma das garantias do controle da 
significação de seus termos e consequentemente uma garantia da qualidade da informação por ele representada.

As definições serão elaboradas observando-se os princípios terminológicos estabelecidos pelas normas da International Standard Organization (ISO, 2000) e os princípios teórico metodológicos que norteiam o projeto, como a Teoria do Conceito (DHALBERG, 1978) a Teoria Comunicativa da Terminologia (CABRÉ, 1995) e as metodologias para construção de vocabulários controlados (AUSTIN; DALE, 1993; ISO, 2011).

\section{Considerações finais}

De acordo com Pombo (2010) atualmente, o conhecimento científico exige um olhar transversal porque está se organizando em forma de rede neural, onde as relações são múltiplas e irregulares. Isto tem sido observado durante as atividades de pesquisa no Eletromemória II, por ser um projeto interdisciplinar com um objeto único que vem sendo estudado e construído sob o ponto de vista de diferentes domínios. Por esse motivo, é necessária cada vez mais uma precisão terminológica no tratamento das questões referentes à integração das áreas, precisão essa que deverá se refletir no vocabulário controlado, já que a partir da definição de todos os termos será possível relacionar esses termos, por suas características comuns, e indexar os documentos agrupando-os de acordo com seus conteúdos, o que se espera, contribua para a efetiva representação e recuperação da informação sobre a história da energia elétrica paulista. 0 vocabulário controlado deverá conferir ao sistema de informação a ser implementado, eficácia e ganhos no processo de circulação da memória da eletrificação, atualmente dispersa em diversas instituições.

\section{Referências}

AUSTIN, D.; DALE, P. Diretrizes para o estabelecimento e desenvolvimento de tesauros monolíngues. Brasília: IBICT; SENAI,1993.

BARITÉ ROQUETA, M.G. La definición de conceptos y su impacto sobre la representación del conocimiento com fines documentales. In: CONGRESO ISKO, 5., 2001, Madrid. Actas, Madrid: ISKO, 2001. p.88-101.

BARROS, L. A. Curso básico de terminologia. São Paulo: Edusp, 2004.

CABRÉ, M.T. La terminologia hoy: concepciones, tendencias y aplicaciones. Ciência da Informação. Brasília, v.24, n.3, p.289-298, set./dez. 1995.

DAHLBERG, I. Teoria do conceito. Ciência da informação. Rio de Janeiro, v.7, n.2, p.101-107, 1978.

DAHLBERG, I. Uma teoria para o Interconcept: teoria analítica do conceito voltada para o referente. International Classification. v.5, n.3, p.142-145, 1978.

FENDRICH, L.J.; PEREIRA, L. Ensinar e Aprender no Ensino Superior Através de Mapas Conceituais In: SIMPEP, 8., 2006. Anais, Bauru.

ISO 1087-1:2000. Terminology work - Vocabulary, Part 1: theory and application/Travaux terminologiques - Vocabulaire - Partie 1: théorie and application. Genève : International Standard Organization, 2000.

ISO 704:2000. Terminology work - principles and methods. 2nd ed. Genève : International Standard Organization, 2000.

ISO 25964-1. Information and documentation - Thesauri and interoperability with other vocabularies part 1 - Thesauri for information retrieval. Genebra : ISO, 2011. 
POMBO, O. Dispersão e unidade: para uma poética da simpatia. In: LARA, M.L.G.; SMIT, J.W. (orgs.) Temas de pesquisa em Ciência da Informação. Universidade de São Paulo, 2010.

ROVIRA, C. DigiDocMap conceptual maps editor and Topic Maps norms. Hipertext.net, n.3, 2005. Disponível em: <http://www.hipertext.net>. Acesso em 14 dez 2014.

LIMA, V. M. A. ; TÁLAMO, M. F. G. M. ; LARA, M. L. G. ; HILSDORF, C. ; JESUS, E.A. . O vocabulário controlado do projeto Eletromemória. In: Simpósio Eletromemória: história da energia elétrica em São Paulo, 2009, São Paulo. Simpósio Eletromemória: história da energia elétrica em São Paulo. São Paulo : Fundação Energia e Saneamento, 2009.

THEW32. Disponível em: <http://publish.uwo.ca/ craven/thew32/thew32.htm>. Acesso 14/12/2014. 